\title{
THOMAS JEFFERSON: ENTRE EL LIBERALISMO Y EL REPUBLICANISMO. LA POSICIÓN DE HANNAH ARENDT
}

\section{THOMAS JEFFERSON: BETWEEN LIBERALISM AND REPUBLICANISM. THE POSITION OF HANNAH ARENDT}

\section{Elisa Goyenechea}

Universidad Católica Argentina

Eligoye@gmail.com

Resumen: El trabajo examina la interpretación de Hannah Arendt del pensamiento político de Thomas Jefferson. En primer lugar, presentamos los principales argumentos que lo ubican en el marco de las ideas del liberalismo. Al respecto, en sus escritos del período pre revolucionario Jefferson alude a la antigua constitución sajona y a los derechos naturales de John Locke. En segundo lugar, exponemos la posición de Hannah Arendt respecto de la Revolución americana como réplica del republicanismo clásico, en desmedro de la tesis prevaleciente hasta 1960, que la ubica bajo la égida del liberalismo clásico. En este contexto, mostramos que la autora interpreta a T. Jefferson como representante del republicanismo, destacando, en particular, su tesis sobre el sistema de consejos.

Abstract: The paper examines Hannah Arendt's interpretation of Thomas Jefferson's political thought. First, we put forward the main arguments that place him within the framework of political liberalism. In this regard, his writings of the pre-revolutionary period allude to the ancient Saxon constitution and to the natural rights of John Locke. Second, we expose Hannah Arendt's assessment of the American Revolution as a replica of classical republicanism, to the detriment of the thesis prevailing until 1960, which places it within the context of classical liberalism. We assert that she interprets T. Jefferson as representative of republicanism, highlighting in particular his thesis on the council system. 
"It has also been a great solace to me to believe that you are engaged in vindicating to posterity the course we have pursued for preserving to them, in all their purity, the blessings of self-government, which we had assisted too in acquiring for them." (Jefferson tenía 82 años cuando, preocupado por su legado, escribió esta carta a James Madison, el 17 de febrero de 1826). ${ }^{1}$

"The councils say: We want to participate, we want to debate, we want to make our voices heard in public, and we want to have a possibility to determine the political course of our country". (Hannah Arendt, Crises of the Republic, A Harvest Book. Harcourt Brace \& Company, San Diego, New York, London, 1973; cf. p. 232).

Este trabajo busca poner en evidencia la recepción de algunos aspectos del pensamiento de Thomas Jefferson por parte de Hannah Arendt. En On Revolution (1963), la pensadora pone en tensión las dos Revoluciones del siglo XVIII, la francesa y la estadounidense. En el marco de ésta última, aborda el pensamiento de los Padres Fundadores y el de Thomas Jefferson, en particular. Nos proponemos tres objetivos. En primer término, presentaremos las ideas políticas de T. Jefferson en el marco del liberalismo y bajo la égida del Second Treatise on Civil Government2, de John Locke. En segundo lugar, desarrollaremos brevemente la posición de Arendt sobre la Revolución Americana como réplica del

1. Cf. Jefferson, Thomas, The Works of Thomas Jefferson, Federal Edition (New York and London, G. P. Putnam's Sons, 1904-5). Vol. 12. [Online] available from $\underline{\text { http://oll.libertyfund.org/ }}$ titles/808; accesed 14/2/2018; Internet (Formato Ebook); cf. p. 279.

2. Locke, John, Second Treatise of Government. Edited, with an Introduction, by C. B. Macpherson, Hackett Publishing Company, Inc., Indianapolis. Cambridge, 1980. republicanismo clásico, en desmedro de las posiciones prevalecientes hasta el 60 que la ubican en el marco del liberalismo clásico ${ }^{3}$. El republicanismo clásico y el humanismo cívico con sus ideas de igualdad y participación, destaca el rol central de la virtud cívica en la preservación del ideal clásico de la libertad política. ${ }^{4}$ Como dice Helena Béjar, Arendt es pionera al respecto pues On Revolution (1963) introduce esta novedad aportando evidencia de las ideas y convicciones afines al republicanismo en sus Padres Fundadores ${ }^{5}$, varios años antes de Pocock en su The Machiavellian Moment (1975), quien asume la posición de Arendt sin darle el debido crédito ${ }^{6}$. Tercero, indagaremos particular-

3. El texto clásico al respecto es el de Louis Hartz, The Liberal Tradition in America, Harcourt Brace and World, New York, 1955.

4. Para precisar la naturaleza y la procedencia del republicanismo clásico o "humanismo cívico", véase Hans Baron, In Search of Florentine Civic Humanism. Essays on the Transition from Medieval to Modern Thought. Volume II, Princeton University Press, Princeton, New Jersey, 1988; cf. pp. 101-151. También, del mismo autor, The Crisis of the Early Italian Renaissance: Civic Humanism and Republican Liberty in an Age of Classicism an Tyranny, Princeton University Press, Princeton, New Jersey, 1966; cf. pp. 3- 46.

5. Béjar, Helena, El corazón de la república: avatares de la virtud politica, Paidós, Barcelona, 2000; cf. pp. 67-69. Dice Béjar: “[...] Arendt conecta ambas revoluciones con la resurrección del mundo clásico y de la República que defendían Harrington, John Milton y Montesquieu. Con ello se adelanta en más de diez años a los historiadores republicanos centrales como Pocock, Skinner o Wood, que apenas la citan".

6. En el capítulo XV, "The Americanization of Virtue: Corruption, Constitution and Frontier", de The Machiavellian Moment, Princeton University Press, Princeton and Oxford, 1975, Pocock alude a On Revolution (en la p. 516) y a The Human Condition, más extensamente (en la p. 550). En esta última, afirma que ha toma- 
mente la interpretación de Hannah Arendt del pensamiento político de T. Jefferson. Sostenemos que la pensadora interpreta al autor de la Declaración de la Independencia en el marco del republicanismo clásico destacando su defensa de la democracia participativa a través del sistema de consejos (ward system), a los que llamó "repúblicas elementales"7. Entendemos que su concepción del "espíritu revolucionario"8 y sus nociones clave de "espacio público"9 y de "praxis mancomunada"10 son, en gran medida, deudoras de las ideas de Jefferson. Buscaremos probar nuestra posición refiriendo e interpretando los fragmentos más significativos de ambos autores en donde se evidencia la deuda.

Los estudios especializados sobre Thomas Jefferson señalan tres fuentes decisivas de su pensamiento ${ }^{11}$. Primero, el liberalismo clásico fundado en el Second Treatise... de John Locke, compatible con la idea de un gobierno moderado, esencialmente limita-

do de Arendt la idea de homo politicus (Arendt no emplea ese término. Alude al "orador" y al "agente") como tipo humano distinto del homo credens, del homo mercator y del homo faber.

7. Jefferson emplea la expresión en la carta a Joseph Cabell del 2 de febrero de 1816.

8. Arendt, Hannah, On Revolution (Introduction by Jonathan Schell), Penguin Books, New York, 2006; cf. pp.165, 195, 213.

9. Arendt, Hannah, The Human Condition (With an Introduction by Margaret Canovan), The University of Chicago Press, Chicago and London, 1978; cf. pp. 35, 56-57.

10. Cf. idem; pp. 123, 162.

11. Meacham, Jon, Thomas Jefferson: The Art of Power, Random House, New York, 2012; cf. Part I, Chapter 3: "Roots of Revolution"; Part II, Chapter 9 and 10: "The Course of Human Events", "The Pull of Duty". Maier, Pauline, American Scripture. Making the Declaration of Independence, Random House, New York, 1998; cf. pp. 34-45; 69-95. do, cuyo fin es la protección de los individuos y sus libertades garantizadas constitucionalmente. Segundo, el republicanismo clásico, desde Aristóteles hasta Maquiavelo y Harrington, con sus ideas de virtud cívica, libertad política y compromiso activo; teoría que incluye un fuerte contenido ético y que reclama una particular visión antropológica y de la comunidad humana, cuya fuente es Aristóteles. Tercero, las premisas de la ilustración escocesa, cuya influencia estudian Gilmar Ostrander en su artículo, "Jefferson and the Scottish Culture", y Daniel Robinson en "The Scottish Enlightenment and the American Founding"12. Nuestro trabajo no indagará esta tercera línea de influencia.

A continuación, seguiremos el siguiente orden: primero, identificaremos los postulados del liberalismo clásico en Thomas Jefferson, destacando los fragmentos más significativos de dos obras del período revolucionario: A Summary View of The Rights of British America (1774) y Declaration of the Causes and Necessity of Taking Up Arms (1775) ${ }^{13}$. En particular, recalaremos en su invocación de las libertades sajonas de la Ancient Constitution inglesa y en su apropiación de las premisas lockeanas, en relación a su modo novedoso de concebir el imperio británico. En segundo lugar, señalaremos sucintamente la interpretación que realiza Hannah Arendt de la Revolución americana, como réplica del republicanismo clásico, en desmedro de la

12. Robinson, Daniel N., "The Scottish Enlightenment and the American Founding", The Monist, vol. 90, no. 2; cf. pp. 170-181. Puede consultarse también: Ostrander, Gilman M., "Jefferson and Scottish Culture", Historical Reflections / Réflexions Historiques, vol. 5, no. 2, 1978, pp. 233-249. (www.jstor.org/stable/41298719).

13. Por razones de espacio, no nos referiremos a Declaration of Independance (1776) y al First Inaugural Speech (1801), en los que también se encuentra esta temática. 
posición prevaleciente, que la alinea tras los ideales del liberalismo. En ese marco, pondremos en evidencia -en tercer lugarlos tópicos esenciales del republicanismo que ella encuentra en Thomas Jefferson. Entendemos que la preocupación por el autogobierno, la virtud y la participación -la posición de H. Arendt- se encuentra principalmente en su epistolario, y en particular, en las cartas posteriores a 1800.

\section{Thomas Jefferson entre el liberalismo y el republicanismo}

En The Political Philosophy of Thomas Jefferson (1993), Garret Ward Sheldon ubica a Jefferson entre el liberalismo y el clasicismo ${ }^{14}$. Cierto es que las premisas del liberalismo y las del republicanismo predominan en períodos bien diferenciados, siendo lockeano durante el período revolucionario y anti-federalista, y republicano durante el período de construcción nacional post-revolucionario. Sin embargo, tras una lectura atenta, ambas vertientes atraviesan sus escritos durante su vida. En The Creation of the American Republic, 1776-1787 (1969), Gordon Wood defiende la tesis de una amalgama de ideas filosóficas reunidas en un todo comprehensivo y coherente. Para el historiador, Jefferson no habría considerado contradictorio defender al mismo tiempo la protección de los derechos naturales individuales y la participación popular de las repúblicas democráticas clásicas ${ }^{15}$.

14. Sheldon, Garret Ward, The Political Philosophy of Thomas Jefferson, The John Hopkins University Press, Baltimore \& London, 1993; cf. pp. 1-8

15. Wood, Gordon, The Creation of the American Republic, 1776-1787, Chapel Hill, University of North Carolina Press, 1969; cf. pp. 3-10.
Más aun -defiende Wood- él creía que la participación asidua y comprometida de los ciudadanos funcionaría como garantía de la preservación de los derechos ${ }^{16}$. En efecto, en sus obras del período revolucionario, T. Jefferson toma una posición cercana al liberalismo lockeano, que predomina contra el parlamento y contra los federalistas al defender una república de legislaturas autónomas en las colonias o en los estados. Al mismo tiempo, su defensa de la república clásica (o sea, participativa) en todos los niveles de organización política, es decir, tanto en el consejo, como en el condado, en el estado y en el gobierno nacional (propia del segundo período), conduciría directamente a la protección de los derechos y las libertades individuales del gobierno tiránico. Contrario a James Madison, quien veía en la participación popular mayoritaria una amenaza potencial a los derechos individuales ${ }^{17}$, Jefferson vinculaba estrechamente ambas circunstancias, por lo que -argumenta Wood- tuvo éxito en fusionar las ideas republicanas clásicas con las liberales lockeanas.

Si la lectura de Gordon Wood es acertada, entonces la praxis concreta de los ciudadanos, reunida en las ideas de participación popular y de compromiso activo, constituiría el medio instrumental propicio para el verdadero fin la política, que coincidiría con la garantía de las libertades civiles y la defensa de los derechos consagrados por la Constitución. O sea, si seguimos esta lectura, el republicanismo de T. Jefferson sería subalterno de su liberalismo y -en los términos de Arendt- la participación activa en la cosa pública sería el medio por el que se logran los ver-

16. Idem, cf. pp. 28-33.

17. Cf. The Federalist, 10. 
daderos fines de la vida humana, en este caso, las libertades garantizadas constitucionalmente. Claramente, Hannah Arendt no comparte esta lectura de Jefferson, pues conceptualiza la política como un fin en sí mismo, y entiende que esta perspectiva es compatible con las ideas del propio Jefferson.

Cuando Arendt cuestiona la gran tradición de pensamiento político occidental, especialmente en Was ist Politik? (1993) y en The Human Condition (1958), defiende un modo de entender la política diverso del inaugurado con Platón, el iniciador de la Filosofía política ${ }^{18}$. Su posición es que desde Platón la política se entendió como un medio para fines más elevados (en su caso, la paz y el orden para la actividad filosófica), todos ellos, con independencia de su contenido, se ubican fuera de la política ${ }^{19}$. En otras palabras, a partir de la filosofía política, que Platón inaugura, encontramos una versión precoz de la invasión de la razón instrumental, en perjuicio de la razonabilidad o la sensatez fronética. De allí el título del parágrafo 31 de The Human Condition: "La tradicional substitución de actuar [acting] por hacer [making]"20. Fundando su interpretación en poetas e historiadores previos a la escuela socrática, Arendt entiende la política como un fin en sí mismo, como espacio de despliegue de la praxis conjunta (como algo distinto de la destreza técnica $)^{21}$ y de la libertad como un hecho

18. Arendt, Hannah, "Philosophy and Politics", Social Research, Vol. 57, No. 1 (Spring 1990), pp. 73-103; cf. pp. 76-78, 94-96, 99-102.

19. Arendt, Hannah, Was ist Politik? Aus dem Nachlass, Pieper Verlag, München, 1993; cf. pp. 28-70.

20. Arendt, Hannah, The Human Condition, op. cit.; cf. pp. 220-230.

21. Idem, cf. pp. 195, 205-207. a la vista de todos (como algo distinto del libero arbitrio ${ }^{22}$. Para la pensadora, la política comprende las actividades más eminentes de la vita activa -praxis y lexis- por las cuales exhibimos nuestra verdadera humanidad al actuar junto a otros en beneficio de lo que es común a todos ${ }^{23}$. Este modo de entender la política, más cercano a las notas del republicanismo que a la defensa de las libertades negativas, propio del liberalismo, es el que Arendt atribuye a Thomas Jefferson.

Jefferson creció y se formó profesionalmente en el contexto ideológico del imperio británico. G. Sheldon esclarece este concepto asignándole la condición de imperio a la Inglaterra del XVIII y calificándola como un dominio imperial que había asentado colonias en América bajo un monarca absoluto ${ }^{24}$. Los vínculos entre ambos estaban asentados en Cartas Reales y tradiciones feudales. Según Sheldon, las ideas revolucionarias que Jefferson aprendió como estudiante de abogacía contenían los principios políticos generados en Inglaterra en los tumultos entre 1660 y 1688, año que marcó el final de la restauración Estuardo y la llegada al trono de Guillermo III de Orange, con su esposa María II. Particularmente,

22. Arendt, Hannah, Between Past and Future. Eight Exercises in Political Thought, Penguin Books, New York, 1993; cf. pp. 150-152, 161162.

23. Arendt, Hannah, The Human Condition, op. cit.; pp. 7-17.

24. Sheldon, The Political Philosophy of Thomas Jefferson, op. cit.; pp. 22-24. Véase también Carl Becker, The Declaraction of Independence. A Study in the History of Political Ideas, Harcourt, Brace and Company, New York, 1922; cf. cap. III: "Historical Antecedents of the Declaration. Theory of the British Empire". (http://oll.libertyfund.org/titles/becker-the-declaration-of-independence-a-study-on-the-history-of-political-ideas). 
la invocación a la Ancient Constitution, a las libertades sajonas, y a los derechos naturales de Locke, las armas teóricas que el Parlamento había esgrimido para destituir a Jacobo II. Entendemos que T. Jefferson adaptó estas ideas convenientemente para su batalla ideológica por la independencia de las colonias, inclusive al precio de caer en ambigüedades e inconsistencias, como veremos. Mostraremos, además, que empleó nociones clave del pensamiento de John Locke para reformular, en términos modernos, la noción tradicional de imperio.

\section{1.l Jefferson y la antiqua Constitución sajona}

Jefferson transitó los años previos a la revolución con temor, por las posibles acusaciones de traición y la perspectiva de la muerte, y con angustia, por el corte con los lazos tradicionales con la madre patria $^{25}$. En la Declaration of Independence, alude claramente al dolor de la ruptura de lazos afectivos e inclusive sanguíneos ("brethren"), pero al mismo tiempo consigna que la medida de la opresión que las colonias están dispuestas a soportar ha sido sobrepasada y su paciencia, colmada: "Cuando la corona fue a la guerra contra las colonias [...] con mercenarios escoceses y extranjeros [...] la última estocada de un afecto agonizante [...] renuncia para siempre a estos hermanos insensibles [...] olvida nuestro antiguo amor por ellos» 26 .

25. Sheldon, The Political Philosophy of Thomas Jefferson, op. cit.;cf. pp. 20 y 21.

26. Becker, Carl Lotus, The Declaration of Independence: A Study on the History of Political Ideas (New York: Harcourt, Brace and Co., 1922). [Online] available from http://oll.liberty-
Desde los primeros asentamientos coIoniales con Elizabeth I, Inglaterra había mudado su fisonomía y estructura, hasta convertirse en un imperio expansivo y dominante. Su estructura imperial ya no respondía a los parámetros tradicionales de la monarquía feudal, ámbito en que las colonias habían sido asentadas en el XVII. Esta "ideología imperial", involucraba convicciones, parámetros de juicios, pre-conceptos y hábitos de pensamiento que conforman, juntos, la cosmovisión política y social de la época. Con la palabra ideología, se alude a la auto-comprensión que una época tiene de sí misma y al modo en que los humanos en determinada época, se comprenden a sí mismos y actúan en consecuencia ${ }^{27}$. Las ideas y conceptos,

fund.org/titles/1177; accessed 2/2/2018; Internet. (Formato Ebook PDF); cf. p. 73. (Todas las traducciones son nuestras).

27. Para el uso de la palabra ideología véase Joyce Appleby, "Republicanism and Ideology”, American Quaterly, Vol. 4, n. 7, 1985; pp. 461-473. (Stable URL: http://www.jstor.org/stable/2712577). Appleby recala en la diferencia entre idea e ideología y afirma que las ideas no pueden orientar la praxis a menos que se hayan encarnado en una estructura social. O sea, cuando expresan la auto-comprensión de esa comunidad en una determinada etapa. Appleby alude al cap. 2 (p. 35), del texto de B. Bailyn, The Ideological Origins of the American Republic, donde el autor alude a la ideología como un "conmutador intelectual conectado de modo tal que una serie dada de acontecimientos ponía en acción un juego claro de señales". Dice Appleby: "he [Bailyn] replaced the tired old notion of intellectual influence with the exciting concept of ideology. Ideas, Bailyn maintained, only influence political action when they are part of a socially-created structure. The Cassandras of the British Opposition shaped events in America because their opinions organized attitudes otherwise too vague to be acted upon, because, as he said, they crystallized otherwise inchoate discontent. Ideas, to use Bailyn's metaphor, compose themselves into intel- 
por sí solos, no pueden orientar la praxis a menos que estén encarnados en una estructura social. Se vuelven ideología cuando expresan la auto-comprensión de una comunidad en una determinada etapa e inspiran sus acciones.

La cosmovisión o ideología imperial involucraba política, economía, sociedad y religión en un todo integrado y armónico gobernado por un solo soberano bajo una ley natural, cuya fuente era Dios. Esta visión de una totalidad integrada tradicional fue trasladada a las colonias y a todo el imperio. Suponía una dependencia asentada en vínculos feudales y en la fidelidad al rey. El control de la corona sobre la política de las colonias era generalizada. La legítima posesión de las tierras era garantizada por Carta real, los funcionarios, gobernadores y consejos eran nombrados por la Corona; las leyes, promulgadas por asambleas públicas menores, eran enviadas a Londres para la aprobación real y regresaban como Decretos Reales. La auto-comprensión de los colonos estaba ligada a su pertenencia a esta estructura imperial feudal.

Tras la Glorious Revolution de 1688 y el Act of Settlement de 1701, el paradigma de la monarquía tradicional se modifica y deja paso al establecimiento de la supremacía parlamentaria. Es decir, la soberanía se desplazó de la Corona al Parlamento, y el Imperio Británico se volvió más comercial pues este estamento se volvió cada vez

lectual switchboards [conmutadores intelectuales] wired so that certain events almost surely will provoke particular reactions. The colonial elite, confronting the Parliamentary reforms of the 1760s, for example, was compelled to interpret the new measures as signs of a tyrannical impulse in England because this unexpected exercise of power tripped existing fears about the unbalancing of the constitutional order which preserved Englishmen in their liberties and estate". más influyente en el Parlamento. Acaece un cambio de paradigma. Los intereses mercantiles, la expansión territorial y las atribuciones desmedidas que se arrogó el Parlamento primaron por sobre la antigua conducta del imperio feudal ${ }^{28}$. En el lugar de una dependencia integral basada en vínculos feudales en la gran familia de estados o colonias, las colonias se volvieron objeto de preocupación e interés en vistas de los beneficios pecuniarios, que podían reportar al imperio (fundamentalmente para saldar deudas). Ahora bien, aun si el Parlamento y sus ambiciones expansionistas comerciales tomaron el control del imperio, este aún retenía la estructura, las ideas y pre-conceptos explicativos de la "benigna ideología real"29, que en origen lo estableció. Según Sheldon, una conducta primordialmente comercial y agresiva, pero revestida del ropaje de una cosmovisión tradicional influyó en la confusión, abonó el resentimiento y, finalmente, activó el deseo de independencia de las colonias.

La expresión teórica de ese deseo en las colonias empleó las mismas armas ideológicas con las que el Parlamento inglés había tumbado la monarquía, casi cien años antes. Es decir, la invocación de la Ancient Constitution y de los derechos naturales, fueron el principal argumento usado por los colonos en América, y por Jefferson en particular, para derribar los vestigios de la supremacía real, a saber, la ideología tradicional del imperio bri-

28. Para el tema de la supremacía parlamentaria y el derecho del Parlamento a imponer impuestos a las colonias, véase: Reid, John Phillip, Constitutional History of the American Revolution, The University of Wisconsin Press, Wisconsin and London, 1995; cf. Chapter 2: "The Authority to Tax", cf. pp. 26-47.

29. Sheldon, G. W., The Political..., op. cit.; cf. p. 24. 
tánico. Se trata, repetimos, de las ideas británicas del período 1660-1688, que culminó con la abdicación de Jacobo II, la entronización de Guillermo III de Orange, y la Bill of Rights (de 1689) ${ }^{30}$. Las ideas independentistas de Thomas Jefferson

30. El historiador británico y neozelandés, J. G. A. Pocock, en cambio, vincula los eventos con el affair Walpole y la reacción republicana al comercialismo de 1690-1740. La diferencia de posturas no alude solamente a los treinta años que median entre ellas, sino a la verdadera fuente de la ideología emancipatoria en las colonias. Si las ideas políticas inglesas que alimentaron la revolución en América eran de cien años atrás (los principios que alimentaron la Glorious Revolution), entonces se trata de los principios antimonárquicos, cuya fuente es la Ancient Constitution y el Second Treatise....de John Locke. Pero si eran del período posterior, cuando el poder del Parlamento y la expansión comercial estaban ya bien afianzados, entonces las ideas inspiradoras de Jefferson habrían provenido del republicanismo clásico y sus ideas de virtud y frugalidad. Véase, Pocock, The Machiavellian Moment. Florentine Political Thought and the Atlantic Republican Tradition. (With a new afterworld by the author), Princeton University Press, Princeton and Oxford, 1975; cf. pp. 122-126, 426. La idea clave de la oposición -esclarece Pocock en su "Afterword" a The Machiavellian Moment, de 2002, no era tanto el auge del comercio sino el crédito, y el reclamo de conducta virtuosa frente a la corrupción del clientelismo (political patronage). Cf. idem, pp. 579-581. Pocock minimiza el papel de Locke en la Revolución y la Fundación de los EEUU. Dice en la p. 580: "No existe un prototipo [blueprint] de una república lockeana, y Locke-que estaba más interesado en el origen y el fin del gobierno que en su estructura y ejercicio- se abstuvo cuidadosamente de instruir al pueblo sobre cómo reconstituir al estado, después de haberlo disuelto. Un orden político [polity] lockeano sería una comunidad de portadores de derechos, pero no dice nada sobre su forma, ni de su constitución. Debemos, por lo tanto, mirar más allá de Locke para descubrir por qué se dio por descontado que los nuevos estados independientes serían repúblicas." fueron las proclamas compatibles con el liberalismo lockeano, anti-autoritarias y anti-monárquicas, que desembocaron en la Revolución Gloriosa. Cuando buscaron justificar su separación de la Metrópoli, los patriotas de las colonias americanas -y Jefferson especialmente- insistieron en que la emancipación era el resultado de las reiteradas violaciones de los principios y tradiciones históricas por parte de la madre patria en su trato con las colonias ultramarinas, en particular en su política fiscal discriminatoria e injusta.

Fundaremos esta apreciación que vincula a Thomas Jefferson con las ideas del liberalismo en algunos fragmentos destacados de dos obras del período pre-revolucionario: A Summary View of the Rights of British America (1774) y Declaration of the Causes and Necessity of Taking Up Arms (1775). Allí, Jefferson esgrime dos justificaciones teóricas: primero, la Ancient Constitution como la cuna -históricamente emplazada- de las venerables libertades sajonas, el precedente fundacional para los derechos coloniales. Segundo, el liberalismo lockeano, con su noción clave de los derechos naturales, reforzaba los reclamos coloniales invocando una naturaleza humana supra-histórica, tan universal y abstracta, como los derechos inalienables que fundaba. Además, la herencia de John Locke y la deuda con el liberalismo clásico es evidente en su novedosa concepción del imperio. Ambas fuentes le proveyeron los argumentos que las colonias independentistas necesitaban para justificar teóricamente su desvinculación de una estructura imperial tradicional, a la que consideraban corrupta. Ciertamente, Jefferson denuncia abiertamente la corrupción parlamentaria y la inoperancia del rey, pero al hacerlo no invoca a la virtud republicana (como defiende Pocock), sino que usa el lenguaje 
de los antiguos derechos sajones. Es decir, busca defender las libertades agraviadas y los derechos usurpados. Adaptó a sus propias circunstancias esas venerables y tradicionales verdades -la herencia de las libertades sajonas- y formuló una concepción original del imperio británico confederado.

En The Ideological Origins of the American Revolution, B. Bailyn sostiene que para Inglaterra la Ancient Constitution era considerada la "libertad perfecta", asentada en principios y prácticas de gobierno de las tribus sajonas pre-feudales. El término alude a una edad dorada en los albores de la historia inglesa, que luego sería vulnerada con la invasión normanda y su codificación (siglo XI), con las que llegaron la monarquía y la organización feuda ${ }^{31}$. El paraíso perdido y mítico de la libertad inglesa previo a la incorporación de la estructura e influencias de la autoridad monárquica. Más específicamente, esta antigua constitución sajona era el fundamento último de la salvaguarda de las libertades de los individuos para participar en políticas de gobierno que afectaran su propiedad privada (taxation). El aspecto específico en el que Jefferson recaló, era que la constitución sajona era hostil a la estructura monárquica feudal, que consideraba toda propiedad territorial como posesión y don del soberano. Además, el feudalismo monárquico no consideraba esas distintas esferas de la vida humana como espacios de libertad del individuo, sino como partes integrales de un cuerpo orgánico ordenado piramidalmente bajo la égida de su majestad.

Esta peculiar constitución inglesa fue descripta por John Adams como "la más

31. Bailyn, Bernard, The Ideological Origins of the American Revolution, Belknap Press, Cambridge, Massachusetts, 1967; cf. pp. 67-68, 80-82. perfecta combinación de poderes humanos en sociedad, que la sabiduría finita ha ideado [contrieved] y puesto en práctica para la preservación de la libertad y la producción [production] de la felicidad"32. Para B. Bailyn, en los años previos a la Revolución, los colonos americanos no entendían la palabra constitución como lo podríamos hacer nosotros, como un documento escrito, o inclusive como un diseño de gobierno no escrito, pero deliberadamente elaborado, sumado a una especificación de los derechos, que la legislación no puede tocar. Por el contrario, concebían la constitución como el "orden [arrangement] constituido -es decir, pre-existente- de instituciones gubernamentales, leyes y costumbres, junto con los principios y los fines que las animan"33. Ese sentido de constitución era el invocado por lo colonos, cuando reclamaban a la madre patria por sus derechos usurpados. Como dice Pocock, citando precisamente On Revolution, de Arendt: "En defensa de su virtud contra la corrupción de la tiranía de la monarquía parlamentaria, los americanos empezaron a reconstituirse a sí mismos en una confederación de repúblicas; hasta este punto su revolución fue una rinnovazione"34, es decir, una restauración de libertades antiguas (Constitution). En suma, mientras que los parlamentarios, abogados y jurisconsultos ingleses habían situado su reclamo históricamente sobre bases que antecedían a la monarquía, Jefferson he-

32. Adams, John, The Political Writings of John Adams (Edited with an Introduction by George W. Carey), Regnery Publishing, Inc., Washington, 2000; cf. p. 644.

33. Bailyn, B, The Ideological Origins of the American Revolution, op. cit.; cf. p. 68.

34. Pocock, J.G.A., The Machiavellian Moment, op. cit.; cf. p. 516. 
redó este concepto y lo empleó para sus propios propósitos, que comprendían, inicialmente, la restauración de viejas libertades y, finalmente, la impugnación de la monarquía feudal entendida como tiranía parlamentaria.

Thomas Jefferson vinculó directamente el argumento histórico de la Ancient Constitution con los derechos naturales a-históricos (the Rights of Man), combinando sin escrúpulo razón e historia, teoría y datos empíricos, o como dice Gordon Wood, empirismo y racionalismo ${ }^{35}$. Para el historiador estadounidense, Jefferson buscó reforzar el argumento de la legitimidad histórica con el plus de los derechos naturales de John Locke. En otras palabras, derivó principios universales de los datos históricos contingentes. Al respecto sostiene Wood: "El blend de empirismo y racionalismo de los americanos les concedió cierta permisividad en el uso de la historia [...], a menudo parece que simplemente seleccionan del pasado ejemplos para reforzar generalizaciones deducidas por la pura razón. [...] Sus argumentaciones presentan el delicado equilibrio entre experiencia histórica y verdad auto-evidente. $\mathrm{Y}$ el verdadero riesgo es que las urgencias y necesidades racionales del momento podrían dominar [overpower] la veracidad del pasado"36. Es decir, ante la urgencia política, Jefferson que era más hombre de estado que historiador, interpretó y editó los hechos efectuando un particular "uso de la historia". Vinculó directamente la suerte de las colonias con la recuperación de las libertades sajonas, en desmedro de la herencia normanda, que introducía

35. Wood, Gordon, The Creation of the American Republic, 1776-1787, The University of North Carolina Press, Chapel Hill and London, 1998 (First Edition 1969); cf. p. 8.

36. Idem, cf. pp. 8-9. premisas inconvenientes. Creemos que esta estrategia introdujo inconsistencias en el argumento de Thomas Jefferson. En lo que sigue, mostraremos la ambigüedad del discurso del autor en sus escritos.

\subsection{Perplejidades del discurso de Jefferson}

Para Thomas Jefferson, la Metrópoli usurpó los derechos de los colonos, expoliando riqueza de las tierras coloniales para hacer frente a la descomunal deuda pública contraída para financiar la guerra de los siete años contra Francia (1756-1763). Dice Jefferson: "Ellos [el Parlamento] hablan de hacer cumplir las leyes, cuando están violando la Constitución [...]. ¿Acaso sus ministros -jSeñor!- descubrieron minas de inextinguible riqueza en América, para expoliar, para cancelar nuestra enorme deuda nacional?"37. La Metrópoli pretendía cancelar sus deudas mediante la entrega de tierras, y la alta burguesía terrateniente virginiana, a la que Jefferson pertenecía, quería defender su propiedad ante la amenaza de expropiación. De allí que Jefferson avale una aristocracia propietaria y terrateniente intocable. Pero esta idea -admítase- responde al paradigma de la monarquía feudal, que claramente entra en colisión con su permanente invocación de los derechos sajones, como previos a (y posteriormente contaminados por) la legislación normanda. Quizá Jefferson era consciente de esta inconsistencia en su argumentación y, por eso, usó como principal argumento la voracidad y la extra

37. Cf. Thomas Jefferson The Works of Thomas Jefferson, Federal Edition (New York and London, G. P. Putnam's Sons, 1904-5). Vol. 2. [Online] available from http://oll.libertyfund.org/ titles/755; accessed 28/1/2018; Internet. Véase p. 53. (Formato Ebook pdf). 
limitación del Parlamento: "Mientras que cada día asistimos a un nuevo e injustificado ejercicio de poder sobre sus súbditos del otro lado del agua [on that side the water]. [...] la verdadera razón por la que declaramos estas leyes nulas es que el Parlamento británico no tiene derecho a ejercer su autoridad sobre nosotros" 38 .

Como destaca Garret Sheldon, la principal perplejidad del recurso teórico a una constitución sajona para legitimar los deseos emancipatorios de las colonias, es que la validez histórica del precedente sajón es cuestionable. La noción de una Ancient Constitution esgrimida por los revolucionarios es un peculiar uso de la historia: "una edad dorada, un paraíso perdido en el que los ingleses habrían gozado de libertades que luego fueron usurpadas, y que debían ser restauradas" 39 . Es decir, un relato pergeñado durante el siglo XVII en ocasión de las luchas políticas entre el rey y el Parlamento agraviado. Más específicamente, los parlamentarios que habían procurado fundar sus derechos en alguna fuente diversa de la prerrogativa real y el privilegio feudal, la hallaron en una tradición constitucional pre-feudal anterior a la Corona y preservada en la Common Law. Compelidos a buscar una base para sus reclamos, los constitucionalistas del XVII, "vincularon sus libertades a períodos más y más míticos y remotos en su esfuerzo por probar que esos derechos eran independientes de la voluntad de los reyes"40. Lo decisivo del asunto es que la evocación de la mítica Constitución adolecía de rigurosidad histórica, lo cual le mermaba consistencia

\section{Ibidem.}

39. Sheldon, Garret W., The Political Philosophy of Thomas Jefferson, op. cit.; cf. p. 33.

40. Idem, cf. p. 34. al argumento revolucionario. Glosando a Pocock, Sheldon sostiene que, en rigor, la tradición de la Common Law no alude fundamentalmente a las antiguas libertades sajonas con las que se pretendía fundar la supremacía parlamentaria, sino que codifica las relaciones feudales que llegaron a la isla con William the Conqueror: "La Common Law era ante todo, una ley reguladora de la tenencia de la tierra, la cual presuponía usos [tenures] militares y feudales que los normandos habían importado" 41 .

En suma, por razones de conveniencia, Jefferson aludió a la constitución sajona para pasar por alto la estructura política y jurídica normanda; buscó una fuente que legitimara el derecho absoluto de los individuos propietarios sobre las tierras, para prevenir expropiaciones por deudas ${ }^{42}$. Despachó como "excepcional" la estructura feudal y los derechos de propiedad normandos, y pretendió expulsarlos de la tradición de la Common Law, como meras irregularidades a la norma. Jefferson rechazó el feudalismo por razones pragmá-

\section{Idem, cf. p. 35.}

42. Dice en A Summary View of the Rights of British America : "con el mismo espiritu de imparcialidad e igualdad debería evaluarse la ley del parlamento aprobada durante el 5to año del reinado por la cual las tierras americanas quedan sujetas a las demandas de acreedores británicos, mientras que sus propias tierras en Gran Bretaña están excluidas. Una de las conclusiones obligadas es que la justicia no es pareja en Gran Bretaña y en América o, al menos, que los miembros del parlamento le prestan menos atención aquí que en Londres [else that the British parliament pay less regard to it here than there]." Véase Jefferson, Thomas, The Works of Thomas Jefferson, Federal Edition (New York and London, G. P. Putnam's Sons, 1904-5). Vol. 2. [Online] available from http://oll.libertyfund.org/titles/755; accessed 28/1/2018; Internet. Cf. p. 57 (Formato E-book pdf). 
ticas y enalteció las viejas leyes sajonas, a pesar de que su validez era cuestionable, ya que él mismo reconocía el fundamento real feudal, que las sustituyó. Es decir, Jefferson no niega que el orden feudal importado por los normandos, finalmente, prevaleció. Pero advierte que el origen de ese orden fue la usurpación que sufrieron sus antepasados, que no eran "abogados, sino granjeros". En consecuencia, el axioma que dice que las tierras originariamente pertenecen al rey, es falso. En $A$ Summary View..., leemos: "Nuestros ancestros, sin embargo, quienes emigraron aquí, eran granjeros, no abogados. Fueron tempranamente persuadidos a creer como verdadero, el principio ficticio que dice que originariamente todas las tierras pertenecen al rey". Y continúa diciendo: "La propiedad feudal no era sino una excepción en las leyes sajonas de posesión, bajo las cuales el derecho a la tenencia de todas las tierras era absoluto. Estas leyes aún forman la base, la roca fundacional de la Common Law, que prevalece sin importar las excepciones que hayan ocurrido. América no ha sido conquistada por William el normando, ni sus tierras han sido entregadas a él o a sus sucesores" ${ }^{43}$. Los colonos luchaban por sus derechos históricos, y a Jorge III no se le permitiría convertirse en otro William el normando, que impondría una regla tiránica a los emigrantes sajones en América. Jefferson concluye con una exhortación: "los reyes son los sirvientes, no los propietarios del pueblo. Abra su pecho, Señor, al pensamiento liberal y expandido [ liberal and expanded thought]. Que el nombre de Jorge

43. Jefferson, Thomas, The Works of Thomas Jefferson, Federal Edition (New York and London, G. P. Putnam's Sons, 1904-5). Vol. 2. [Online] available from http://oll.libertyfund.org/ titles/755; accessed 28/1/2018; Internet. Cf. p. 62 (Formato e-book pdf).
III no sea una mancha en las páginas de la historia" 44 .

La carta a Edmund Pendleton del 13 de agosto de 1776 pone en evidencia el pragmatismo de Jefferson. Refiriéndose a la Ancient Constitution y después de admitir la posibilidad de su invalidez, Jefferson simplemente abandona el terreno de la justificación teórica y recurre al de la conveniencia política, declarando el asunto como meramente especulativo ("this matter is now a mere speculative point'). Asimismo, exige una adhesión indeclinable al "feliz sistema de nuestros ancestros" y defiende la "restitución de las antiguas leyes sajonas", en lugar de quedar enredados en la cuestión de su problemática validez ${ }^{45}$.

\subsection{Dos concepciones imperiales. El imperio británico vs. el imperio moderno de Jefferson}

Continuemos ahora examinando algunos párrafos significativos de Jefferson en relación a estas cuestiones. Con respecto a la filiación entre los ingleses (en este caso, los colonos de América) y los sajones, sumado al derecho natural de apropiación de los bienes de la tierra ${ }^{46}$, leemos en $A$ Summary View of the Rights of British America:

\section{Cf. idem, pp. 63-64.}

45. Cf. https://founders.archives.gov/documents/ Jefferson/01-01-02-0205. No hemos hallado la carta a E. Pendleton, en la biblioteca on line de Liberty Fund, de donde preceden todas nuestras citas referidas a los escritos de Jefferson.

46. Locke, John, Second Treatise..., op. cit.; p. 19. Dice: "Whatsoever then he removes out of the state that nature hath provided, and left it in, he hath mixed his labour with, and joined to it something that is his own, and thereby makes it his property". 
"Nuestros ancestros, antes de su emigración a América, eran habitantes libres de los dominios británicos en Europa, y poseían un derecho que la naturaleza ha dado a todos los hombres, de partir del país en el que viven, no por elección, sino por azar, y de ir en busca de nuevas tierras, y establecer nuevas sociedades, bajo las leyes y las regulaciones que mejor promuevan la felicidad pública. Bajo esta ley universal, sus ancestros sajones, de la misma manera, abandonaron sus bosques y sus tierras nativas en el norte de Europa, y poseyeron ellos mismos la isla de Bretaña, en ese entonces menos poblada y establecieron allí ese sistema de leyes, que ha sido, desde hace tanto tiempo, la gloria y la protección de ese país." (Jefferson, T., The Works of Thomas Jefferson, op. cit.; cf. p. 54).

A renglón seguido defiende la continuidad ininterrumpida de británicos y sajones pues "no hay ninguna circunstancia que distinga materialmente la emigración británica de la sajona"47. Es decir, su estrategia es evitar la mediación de los códices normandos de propiedad compatibles con la organización de una estructura monárquica y feudal, en la tradición de la Common Law, en la que los colonos se insertaban en calidad de herederos.

Con el objetivo de defender los derechos de los colonos frente a una política fiscal abusiva por parte de la Metrópoli, T. Jefferson formula una teoría del imperio original y moderna, con la incorporación de premisas lockeanas. Jefferson entiende el imperio británico como una federación de legislaturas iguales e independientes,

47. Jefferson, Thomas, The Works of Thomas Jefferson, Federal Edition (New York and London, G. P. Putnam's Sons, 1904-5). Vol. 2. [Online] available from http://oll.libertyfund.org/ titles/755; accessed 28/1/2018; Internet (Formato Ebook pdf). Cf. p. 54 . tanto las coloniales (la Commonwealth de Virginia, la de Pennsylvania, etc.), como la doméstica (el Parlamento en Inglaterra). Estos estados iguales e independientes eligen luego un rey, cuya función es la del juez, que protege los derechos de cada legislatura de toda amenaza de potencias extranjeras y que arbitra en los conflictos entre ellas. Al igual que el gobierno árbitro creado por Locke por individuos iguales e independientes a partir del estado de naturaleza ${ }^{48}$, la Corona Británica, ejercería -en el esquema de Jefferson- un poder delegado y estrictamente limitado a la protección de los derechos de las legislaturas iguales e independientes que componían el Imperio (o sea, la idea de mild government).

Para John Locke, abandonar el estado de naturaleza significa que cada hombre debe deponer su poder de defenderse, cuando sus derechos naturales son violados. El poder de ejecutar la ley natural ya no está en sus manos, sino en la comunidad política. Dice Locke: "la sociedad política se dará allí y sólo allí donde cada uno de sus miembros se haya despojado de este poder natural, renunciando a él y poniéndolo en manos de la comunidad [...] [que] se convierte en el árbitro que [...] dictamina sobre todas las diferencias que puedan tener lugar entre los miembros de esa sociedad"49. Los atributos de la sociedad civil de Locke son desplazados por Jefferson a la estructura imperial. Así como en Locke "las personas [...] se unen en un cuerpo y disponen de una ley común así como de una judicatura a la que apelar, con autoridad para decidir en las controversias que surjan entre ellos y

48. Locke, John, Second Treatise.., op. cit.; cf. pp. 9, 14. (Las traducciones son nuestras).

49. Cf. idem, p. 46. 
poder para castigar a los delincuentes" 50 , en Jefferson el monarca árbitro tiene el deber de intervenir cuando una de las legislaturas pretende usurpar los derechos de las otras. El comportamiento tiránico, sostiene Locke, disuelve la autoridad legítima y restaura la libertad natural y la igualdad, que existe en el estado de naturaleza ${ }^{51}$. Jefferson sigue a Locke cuando apela a "los sagrados y soberanos derechos de castigar [punishment] reservados en manos del pueblo en casos de emergencia"52. Y también cuando denuncia que el Parlamento "[your Ministers] han roto las barreras legales de la constitución y destruido las distinciones de [poder] del gobierno"53.

Jefferson exhorta al rey a velar por la igualdad entre las legislaturas y a impedir que una usurpe los derechos de las otras: "Por lo tanto, ahora es la gran función de Su Majestad, hacer ejercicio de su poder negativo [to resume exercise of his negative power], y evitar que una legislatura del imperio promulgue leyes que resulten injuriosas para los derechos e intereses de otra"54. El gobierno árbitro tiene un poder estrictamente limitado en naturaleza y alcance: proteger a la comunidad sin interferir en la vida de los individuos. Es un árbitro pasivo, que sólo interviene cuando hay disputas, de allí que Jefferson le reclama al rey que ejerza su poder

50. Cf. idem, p. 47

51. Cf. idem, pp. 65-68.

52. Jefferson, Thomas, The Works of Thomas Jefferson, Federal Edition (New York and London, G. P. Putnam's Sons, 1904-5). Vol. 2. [Online] available from http://oll.libertyfund.org/ titles/755; accessed 28/1/2018; Internet (Formato Ebook pdf); véase p. 55 .

53. Cf. idem, p. 52.

54. Thomas Jefferson The Works of Thomas Jefferson, op. cit.; cf. p. 60. "negativo", como reza el fragmento antedicho. En Locke, el poder del árbitro surge y depende del contrato que hicieron los individuos para conformar la sociedad civil y política. En el esquema de Jefferson, su poder es delegado y proveniente de las legislaturas que, en plano de igualdad, conformaron el imperio. Al respecto, en A Summary View..., designa al rey como "el vínculo central [central link] conectando las distintas partes del imperio, que se había de ese modo multiplicado"55. Jefferson se dirige al rey como "the chief officer of the people" 56 , el principal funcionario del pueblo.

Para Locke el propósito principal de la sociedad política es proteger los derechos de propiedad en sentido amplio, esto es, "la vida, la libertad y los bienes [life, liberty and estate]"57. Estos derechos existen antes de la constitución de la sociedad política e inclusive en la misma sociedad política, de allí que, para Jefferson, imponer impuestos sin el consentimiento de sus miembros, u obligar a las colonias a hacer negocios sólo con la Metrópoli, supone invadir sus derechos. Thomas Jefferson argumenta que los derechos de los colonos a su vida, libertad y bienes ["liberty, fortunes and lives"58] derivan directamente de los derechos sajones, o sea, que son previos a la organización monárquica y feudal de los conquistadores normandos. Le advierte a Jorge III, que la ruina de las libertades de los colonos será, también, su propia perdición: “[...] podría terminar siendo la ruina de ambos: ¡usted, Señor! Podría perder su soberanía

55. Cf. idem, p. 55.

56. Cf. idem, p. 54.

57. Locke, John, Second Treatise..., op. cit.; cf. p. 46.

58. Jefferson, Thomas, The Works of Thomas Jefferson, op. cit.; cf. p. 51. 
y su honor; nosotros, nuestras libertades, nuestras fortunas y nuestras vidas."59

En Declaration of the Cause and Necessity of Taking Up Arms ${ }^{60}$ (1775), Jefferson recurre claramente a John Locke para teorizar sobre la nueva forma del imperio. Alude a las distintas partes del imperio como "amigos vinculados por pactos"61 bajo un mismo rey. Respecto de los ancestros que emigraron y formaron sociedades en América, dice: "Para continuar su vínculo con los amigos que habían dejado atrás, se organizaron por medio de convenios [Charters of Compact] bajo el mismo rey común, quien así completó [...] el vínculo de unión entre las distintas partes del imperio"62. Desde el punto de vista de Jefferson, la usurpación comenzó cuando una de las legislaturas del Imperio confederado -el Parlamento británico- se convirtió en el legislador de otras legislaturas libres e independientes (las colonias) y el árbitro -sólo en teoría neutral- colaboró con los usurpadores. Denuncia los intentos de "la Legislatura de Gran Bretaña de establecer un gobierno absoluto sobre estas colonias"; "de obtener el derecho de legislación absoluta [unbounded

\section{Cf. ibidem}

60. Existen dos borradores del documento, que fue expedido por el Segundo Congreso Continental, en julio de 1775 para dar las razones por las que las trece colonias tomaban las armas contra Gran Bretaña. El primero, más radical en su formulación, es de Jefferson, el segundo es de John Dickinson, quien incorporó los argumentos y el lenguaje del primer borrador. Hemos citado fragmentos de ambos.

61. Jefferson, Thomas, The Works of Thomas Jefferson, Federal Edition (New York and London, G. P. Putnam's Sons, 1904-5). Vol. 2. [Online] available from http://oll.libertyfund.org/titles/755; accessed 28/1/2018; Internet. (Formato e-book pdf). Véase p. 77.

62. Cf. ibidem. legislation] sobre las colinas en America"; "de tomar nuestro dinero sin nuestro consentimiento" y de "cambiar la forma de gobierno de una de las colonias"63 (se refiere a Massachusetts, en la que impuso la ley marcial, con las Cohercitive Acts en respuesta al episodio del Tea Party). Denomina esta política como "despotismo de extensión ilimitada"64. Para Jefferson es inadmisible que una de esas legislaturas libres e independientes se arrogue la potestad de suspender o de invadir los poderes de otra y (en A Summary View...) amonesta con las siguientes palabras: "invasiones y usurpaciones intentadas por la Legislatura de una parte del imperio, sobre aquellos derechos que Dios y las leyes han dado a todas ellas, iguales e independientes [those rights which God and the laws have given equally and independently to all]"65.

Clave en su confrontación con el Parlamento son las Cohercitive Acts (para las colonias, "Intolerable Acts") con que la Corona respondió a la rebelión fiscal del suceso del Tea Party. Jefferson defiende a quienes arrojaron millones (en té) a la bahía de Boston, en protesta por las imposiciones tributarias (relativamente bajas en comparación a lo que tiraron al mar), que el Parlamento imponía sobre los productos que las colonias estaban obligadas a obtener comprándole a la madre patria. Leemos: "todos fueron presa de una ruina indiscriminada, a causa de un nuevo poder ejecutivo inaudito hasta ese momento, el del Parlamento británico. Una propiedad valuada en varios millones, fue sacrificada para vengar [revenge], no para pagar [repay], la pérdida de unos po-

63. Cf. idem, p. 78.

64. Cf. idem, p. 82.

65. Cf. idem, p. 54. 
cos miles [se refiere a la carga impositiva sobre el te]. ¡Esto es -verdaderamenteadministrar justicia con mano dura!". Las Intolerable Acts, a las que llama "bloody edict", "han suspendido los poderes de una de las legislaturas americanas [...] y han declarado que pueden legislar por nosotros". Además, "tratan de rebeldes y traidores a los colonos", e imponen "la ley marcial en una de las provincias" [en Massachusetts], [...] destruyendo las vida y la propiedad de sus habitantes"66.

Resumiendo, Jefferson adoptó la tesis pactista de John Locke como la unión de individuos libres e independientes y la trasladó a su visión sobre lo que debería ser el Imperio Británico: una asociación (alianza, Compact/Agreement) de legislaturas iguales e independientes, encabezadas por un monarca-árbitro, cuya función es mediar en los litigios, a fin de que se protejan los derechos y las libertades de cada una. La indeclinable defensa de los derechos de propiedad, condujo a Jefferson a eludir la herencia normanda y a fundar sus argumentos en los derechos de los sajones. Siguiendo a G. W. Sheldon y a B. Bailyn, hemos procurado mostrar que lo que habilitó este peculiar uso de la historia es una modificación de la ideología imperial, un cambio significativo en la auto-comprensión que de si mismos tenían los colonos y los patriotas, que buscaron justificación teórica para la independencia. Dicho con otras palabras, en el marco ideológico del Imperio original y tradicional (o sea, la estructura jerárquica y piramidal) gobernado por la autoridad absoluta de un monarca feudal, la disolución de legislaturas menores o coloniales, no hubiera parecido fuera de lugar. Pero Jefferson alude a otra cosa, pues las circunstancias han cambiado; el monarca

66. Cf. idem, pp. 80 y 82. ha sido suplantado por un Parlamento voraz (una legislatura inferior) que pretende -esto es clave- gobernar las colonias como si fuera un rey. A esto llama Jefferson "tiranía parlamentaria" y alude a las usurpaciones como "medidas tiránicas". ${ }^{67}$

\section{La Revolución americana y el republicanismo: la visión de Hannah Arendt en On Revolution}

Cuando Hannah Arendt teoriza sobre las revoluciones modernas, pone en tensión el evento en Francia y en EEUU, y discrimina las bendiciones que rodearon la revolución en América ${ }^{68}$ y las desgracias que sellaron la suerte y llevaron a su perdición a la francesa ${ }^{69}$. La tesis central de On Revolution (2006) es que el acontecimiento por el que se fundó el cuerpo político de los Estados Unidos, fue una Revolución en la que la violencia brilló por su ausencia. Clave al respecto es el énfasis con que la autora distingue entre república, que es

67. Jefferson, Thomas, The Works of Thomas Jefferson, Federal Edition (New York and London, G. P. Putnam's Sons, 1904-5). Vol. 2. [Online] available from http://oll.libertyfund.org/titles/755; accessed 28/1/2018; Internet. (Formato e-book pdf). Véase p. 56.

68. Hannah Arendt no discrimina entre las distintas revoluciones del continente americano y refiere la Revolución de los EEUU como "the American Revolution".

69. Para un indagación del análisis de Arendt de las dos Revoluciones, véase Ingram, David, "Novus Ordo Saeclorum: The Trial of (Post) Modernity or the Tale of Two Revolutions", en May, Larry and Kohn, Jerome (Ed.), Hannah Arendt. Twenty Years Later, The MIT Press, Cambridge, Massachusetts. London, England, 1997; cf. pp. 221-250. 
el fruto de la Revolución, y gobierno limitado, noción distintiva del liberalismo clá$\mathrm{sico}^{70}$. Arendt dedica muchas páginas de su obra en distinguir entre gobierno limitado y república, entre libertades civiles y libertad política o positiva, entre liberación y constitución de la libertad. En el caso de los Estados Unidos, el momento de liberación, el que usualmente llama la atención por su violencia o por su dramatismo, y ha sido considerado -erróneamente- como la condición per quam de las revoluciones, fue sucedido (sin hiato, sino con sólo con un "compás de espera") por el momento estrictamente revolucionario que la autora identifica con la "pasión constitucionalista" o la "fiebre constitucional" en las trece coIonias $^{71}$. Liberación de o rebelión frente a un gobierno abusivo o colonial -esclarece Arendt- remite a la necesidad de restaurar las libertades antiguas, es afín al reclamo por un gobierno limitado y no tiene nada de revolucionario, sino que puede rastrearse hasta la Carta Magna y los antiguos derechos feudales: la Petition of Rights de 1628, el Habeas Corpus de 1679 y la Bill of Rights de 1689. Allí, se aprecia el afán de restauración mas no de revolución, que ambiciona un cambio radical en la forma de gobierno. La idea de Revolución a diferencia de la de restauración, contiene el elemento del nuevo origen, la discusión por la mejor forma de gobierno y el establecimiento de un nuevo sistema de poderes.

70. Manent, Pierre, Historia del pensamiento liberal, Emecé, Buenos Aires, 1990, cf. pp. 112124.

71. Cf. Arendt, Hannah, On Revolution, op. cit. cf. pp. 139, 165. Las trece colonias que se involucraron en la lucha por la independencia fueron, por el norte: Massachusetts [Nueva Inglaterra], Connecticut, New Hampshire, Rhode Island; en el centro: New Jersey, New York, Delaware, Pensilvania; en el sur: Virginia, Maryland, Carolina del Norte, Carolina del Sur y Georgia.
En una palabra, la noción de Revolución no remite a la exención de los abusos o al control de los órganos de poder, circunstancia que alude a las libertades negativas (incluso el derecho a la representación para decidir sobre las cargas impositivas), sino a la libertad política y a la participación en los asuntos públicos. ${ }^{72}$

Entre las cualidades que la pensadora resalta en el suceso americano es que la guerra de la independencia, el proceso de liberación o rebelión -consustancial a una revolución, pero no su condición suficiente- no arrojó a los colonos a un estado de naturaleza, para decirlo en palabras de Hobbes, sino que los encontró ya organizados en "sociedades políticas" o "cuerpos políticos civiles"73. Tales asociaciones preliminares regulaban sus asuntos con relativa autonomía y -lo que resalta Arendt- recibieron la sanción de las Cartas Reales con posterioridad a su institución espontánea (no tutelado ni guiado por una autoridad superior); fueron súbditos ingleses por casi 200 años hasta su independencia, por lo que no estaban investidos de soberanía. Combinaban, entonces, libertad y no soberanía.

En On Revolution, Arendt interpreta la experiencia colonial y pre-colonial de los EEUU con sus propias categorías de pensamiento político, fraguadas sobre el carácter ejemplar de la polis griega y de la civitas romana. Pertrechada de los instrumentos teóricos antedichos, la autora halla en los orígenes de su patria adoptiva una riqueza política y una experiencia revolucionaria, que no ha sido debidamente enaltecida. Animada con este espíritu, registra en estas "sociedades políticas" coloniales, en las "repúblicas elementales"

72. Cf. idem, pp. 25, 41-45, 50-51.

73. Cf. idem, pp. 158, 167, 186. 
de Thomas Jefferson y en el "Civil Body Politik" de la fórmula del Mayflower una réplica moderna de esas primeras instituciones políticas libres del mundo clásico de las que somos herederos ${ }^{74}$.

La guerra por la independencia, la desvinculación de la Corona inglesa, a diferencia de lo que sucedería en Francia, no barrió los privilegios de los antiguos estamentos y ordenes, que -pertenecientes al antiguo régimen- constituían los patrones de una organización obsoleta; la emancipación lo fue respecto de la Corona inglesa, pero no se sintieron eximidos de sus propios pactos coloniales y Órdenes Fundamentales $^{75}$, en las que yacía su organización.

74. Cf. Arendt, Hannah, On Revolution, op. cit.; p. 159. Leemos: "Estos cuerpos, estrictamente hablando, no eran concebidos como gobiernos; no implicaban gobierno y la división entre gobernados y gobernantes. [...] el pueblo así constituido pudo seguir siendo súbdito real del gobierno de Inglaterra, por más de ciento cincuenta años. Estos nuevos cuerpos políticos eran verdaderamente $<<$ sociedades políticas $>>$ y su gran importancia para el futuro yacía en la formación de un dominio político, investido de poder y con la prerrogativa de reclamar derechos, sin poseer soberanía”.

75. Connectituc, hoy uno de los cincuenta Estados de los Estados Unidos, fue una de las trece colonias, en origen dependientes del Reino Unido. La región, hoy llamada Connecticut, fue explorada en primer lugar por colonos holandeses, que establecieron puestos comerciales, pero los primeros asentamientos permanentes se debieron a los ingleses puritanos de Massachusetts, a partir de 1633. La colonia de Connecticut, desde su origen, gozó de gran autonomía política y fue, en consecuencia, la primera en poseer un Constitución escrita, llamada Fundamental Orders, o First Orders (Mandatos Fundamentales o Primeras Órdenes). Fue adoptada el 14 de enero de 1639 y proclama un principio de gobierno democrático basado en la voluntad del pueblo. Esta constitución colonial serviría de base para la redacción de la Constitución estadounidense, por esa razón se llama a Connecticut "El Estado de la Constitución"
En primer lugar, la suerte de los colonos americanos estuvo predeterminada por su herencia no absolutista, le hacían frente a un gobierno constitucional, la protección de los abusos potenciales de la monarquía les estaba garantizada por el hecho de que gozaban de "los derechos de los ingleses"76. Es decir, el aspecto de-

("The Constitution State"). Para el documento de las Órdenes Fundamentales de Connecticut, véase Grau, Luis, Historia del constitucionalismo americano. Materiales para un curso de historia de las constituciones, Universidad Carlos III de Madrid, Madrid, 2011, cf. pp. 32-35. Para el texto original del Mandato Fundamental de Connecticut, véase: http://oll.libertyfund.org/pages/1639-fundamental-orders-of-connecticut

76. Burke, Edmund, Reflections on the French Revolution, cf. http://oll.libertyfund.org/title/656. Nos referimos a la sentencia de Edmund Burke, que -contra la proclamación de la Revolución Francesa- impugna los derechos naturales inalienables del Hombre y reivindica los derechos históricamente emplazados y sancionados por la tradición. Edmund Burke sostiene que para teorizar o reflexionar sobre la dimensión política de los hombres basta con "constatar o reflejar lo que aparece, dejando de lado la función de penetrar tras las apariencias positivas, forzando su sentido, mediante la aplicación de principios no visibles, que son construcciones racionales". El pensador irlandés, define la sociedad y la historia según el modelo de la naturaleza, en la cual puede descubrirse cierta legalidad y constancia. Lo racional en el plano social e histórico es lo que se ha comprobado como constante e inalterado, aquello que ha resistido al transcurso del tiempo. Para Burke, en consecuencia, la racionalidad y naturaleza del orden social se encuentra en "ciertas constancias inalteradas por el paso del tiempo, es decir, en la tradición". La tradición, entonces, es "el único principio legitimante del orden público". Discute toda defensa de la libertad que tenga por fundamento ideas abstractas sobre el hombre, o que se base en la naturaleza humana y defiende la índole histórica y contingente de los principios. En este caso, "el carácter convencional (no natural) de todo derecho y la sola legitimación de éstos como derechos históricos, como 
cisivamente revolucionario no fue el reclamo por un gobierno limitado y su Constitución -en consecuencia- no se basó en una enumeración de derechos. Si la Revolución de los EEUU, hubiera sido sólo esto, no habría sido más que un reclamo restaurador ante la voracidad impositiva de un Parlamento tiránico o la desmesura de Jorge $\mathrm{III}^{77}$. El aspecto decisivo de la Revolución americana -consigna Arendtes que la cuestión de la Revolución y fundación de un nuevo cuerpo político nunca tuvo su centro en la enumeración de derechos; es decir, en la salvaguarda de las libertades civiles, mediante garantías constitucionales. O sea, la posición de Arendt es que el aspecto crucial del proceso revolucionario en los EEUU no yace en la raíz liberal clásica, sino en la discusión por la mejor forma de gobierno o por la distribución más sabia de los poderes. Veremos que su posición sobre la Revolución es compatible con su interpretación

«herencia del pueblo inglés»". Véase, Molían, Tomás "Burke y las concepciones conservadoras de la democracia", Crítica \& Utopía, Latinoamericana de Ciencias Sociales, número 1, Buenos Aires, septiembre, 1979. Se consultó la versión on line publicada por la Red de Bibliotecas Virtuales de Ciencias Sociales de América Latina y el Caribe de la Red Clacso: www.bibliotecavirtual.clacso.org.ar/ar/libros/criticayutopia.htm Véanse especialmente pp. 1-3. Edmund Burke argumenta sobre los derechos de los ingleses, es decir, los derechos y libertades que se heredan por tradición en Reflections on the French Revolution. Véase, http://oll.libertyfund.org/title/656 Especialmente, pp. 76-77, 81. En esta última leemos: "In the famous law of the 3rd of Charles I. called the Petition of Right, the parliament says to the king, "Your subjects have inherited this freedom», claiming their franchises, not on abstract principles as the "rights of men», but as the rights of Englishmen, and as patrimony derived from their forefathers".

77. Cf. Sheldon, Garret, W., The Political Philosophy of Thomas Jefferson, op. cit.; pp. 19-40, del pensamiento de Thomas Jefferson. Dicho de otro modo, la cuestión esencial fue el establecimiento de un nuevo sistema de poder, o -en palabras de la pensadora- "la constitución de la libertad recién conquistada". En consecuencia, la fuente clave fue el republicanismo clásico ${ }^{78}$. "Constitutio Libertatis"79, es el subtítulo del capítulo IV de On Revolution, titulado "Foundation I"80.

78. Béjar, Helena, El corazón de la República: avatares de la virtud política, op. cit.; cf. pp. 57-82.

79. Cf. Arendt, Hannah, On Revolution, op. cit.; pp. 132-170.

80. La Constitución de los Estados Unidos fue redactada en la Convención Constitucional de Filadelfia, en 1787, ratificada en 1788 (The Federalist) y entró en vigencia en 1789. Es la Constitución de mayor antigüedad que se encuentra, aún hoy, vigente en el mundo. Sustituyó a los "Artículos de la Confederación y Unión Perpetua", que eran los estatutos originales de los Estados Unidos, vigentes desde 1781. Inicialmente, la Constitución definitiva de los Estados Unidos contenía un Preámbulo y siete artículos, en los que se establece el sistema de distribución de poder, o el diseño de las instituciones, lo que Arendt denomina "Constitutio Libertatis". Así, consigna los principios básicos en los que se fundamenta el gobierno federal de los Estados Unidos y los límites a los que tal gobierno está sometido. La mayor objeción que se le hizo a la Constitución durante su proceso de ratificación fue la ausencia de una declaración de derechos fundamentales. Inmediatamente después de ser distribuido el texto Alexander Hamilton publicó en los periódicos de New York un artículo con el título de "The Federalist", bajo el seudónimo Publius. Allí, se comprometía a resolver todas las inquietudes que suscitaba el texto de la Constitución. Para ello, recabó la ayuda de James Madison y de John Jay. Entre octubre de 1787 y agosto de 1788, los autores publicaron en dos periódicos de New York, setenta y siete artículos con el mismo título y bajo el mismo seudónimo. Éstos fueron publicados a fines de 1788 en dos volúmenes con el títu1o "The Federalist. A Collection of Essays written in favor of the new Constitution, as agreed 


\section{Hannah Arendt y el republicanismo de Thomas Jefferson: el sistema de consejos}

Cuando interpreta la historia colonial de EEUU, Hannah Arendt emplea su categoría de praxis y destaca la potencia performativa de las promesas y a las alianzas. Debido a su elasticidad y su operatividad hacia el futuro, no sólo obligan a los ahora contratantes, sino que son virtualmente extensible a las generaciones futuras. Por esa razón, encuentra Arendt en la capacidad de sellar pactos una facultad que erige mundo, suministrando durabilidad y estabilidad, en una medida humana. La medida humana de tal durabilidad garantiza una solidez relativa, no sólo porque las promesas pueden no ser sostenibles a perpetuidad, sino porque el embate de las nuevas generaciones que ingresan al mundo de lo público trae consigo gestos inusitados de praxis y nuevos reclamos. Porque traen renovación, vulneran y amenazan la

upon by the Federal Convention, September 17, 1787'. Los ensayos más famosos son el número 10, en el que Madison trata de cómo impedir la tiranía de la mayoría y la ventaja de un estado grande sobre varios pequeños. En el 39, Madison describe el federalismo y en el 51 introduce la doctrina de los "checks and balances". El 4 de marzo de 1789, el Congreso de los Estados Unidos aprobó doce enmiendas a la Constitución y el 25 de septiembre fueron enviadas a todos los estados para su ratificación. Finalmente, el 15 de diciembre de 1791 diez de ellas se convirtieron en el Bill of Rights, o Carta de derechos, de la Constitución de los Estados Unidos. Hasta ahora, la Constitución ha sido modificada con veintisiete enmiendas. Véase Grau, Luis, Historia del constitucionalismo americano. Materiales para una historia de las Constituciones, op. cit.; en especial pp. 86-98, 119-126. estabilidad del mundo ${ }^{81}$. En suma, este sentido acotado de mundo como espacio público comprende toda la esfera de lo instituido, que emerge de acuerdos y de pactos. Cierto es que la estabilidad es una cualidad inexcusable del espacio público, en general, y de la República, en particular, pues sin ella la vida humana sería imposible. Sin embargo, debe ser flexible a los cambios; se trata, entonces, de una estabilidad relativa. Arendt, al igual que Jefferson, destaca particularmente la intensidad con que las nuevas generaciones ("los recién llegados"82) "toman por asalto" el mundo, que los adultos les entregamos en custodia83, y cuya solidez ha de ser lo suficientemente vigorosa para encauzar su praxis -la estabilidad relativaal tiempo que ha de dejar espacio para cambiar los aspectos, otrora operativos y significativos, pero hoy obsoletos.

La categoría clave del ámbito público y político es la acción; designada con los vocablos griegos praxis y lexis (literalmente: actuar y hablar), la acción responde a la condición humana de la pluralidad ${ }^{84}$. Hablar y actuar siempre acaece entre los hombres. Por su carácter impredecible e ilimitado, no podemos dominar por completo los resultados o de las consecuencias de la praxis, precisamente porque es praxis mancomunada ("action in concert" ${ }^{85}$. Es decir, no controlamos sus implicancias porque hablar y conversar

81. Cf. Arendt, Hannah, The Human Condition, op.cit.; p. 191.

82. Cf. idem, p. 177.

83. Cf. Arendt, Hannah, Between Past and Future. Eight Exercise in Political Thought, op. cit.; p. 182.

84. Cf. Arendt, Hannah, The Human Condition, op.cit.; cf. pp. 7 y 8.

85. Cf. idem, pp. 123, 179. Cf. Arendt, On Revolution, op. cit., cf. pp. 164-166. 
siempre impacta en una red de relaciones e interacciones humanas, imposibles de gobernar.

En relación a estos atributos, Arendt destaca dos aspectos inherentes a la praxis. El primero alude a la capacidad de instituir algo novedoso, de cambiar y de transformar un estado de cosas. Creemos que Arendt enaltece muy especialmente este aspecto de la acción, que podemos llamar ominoso, fatídico e ilimitado: en términos políticos, el aspecto revolucionario. El segundo aspecto de la acción, ineludible para la recta conceptualización del mundo público, alude a todo lo instituido por los hombres: las leyes, las constituciones, los estatutos y reglamentos, en general. Toda institución demarca los límites dentro de los cuales la acción inicia sus cursos, procesos -a su vez- cuyo automatismo, la misma acción interrumpirá86. Es decir, el segundo aspecto, al que podemos llamar conservador, circunscribe la potencial capacidad de innovación de la acción a límites relativamente precisos. En Between Past and Future (1961), la autora identifica estos dos rostros de la acción con dos posiciones políticas y existenciales, la conservadora y la liberal (o progresista). Una, tendiente a mantener el status quo o a restaurar una circunstancia pasada deseable, la otra, proclive a la renovación y el cambio ${ }^{87}$. En On Revolution Arendt profundiza esta postura, aseverando que lo que originariamente fueron dos caras de uno y el mismo fenómeno (el carácter dual de la praxis), con el tiempo se osificó en dos posiciones irreductibles: la conservadora y la liberal. Conservaduris-

86. Cf. Arendt Hannah, The Human Condition, op. cit.; pp. 230-235.

87. Cf. Arendt, Hannah, Between Past and Future. Eight Exercises in Political Thought, op. cit.; cf. pp. 100-102. mo y liberalismo, entonces, designan dos actitudes teóricas con reivindicaciones contrapuestas y en apariencia irreconciliables, pero remiten a la experiencia originaria de la praxis, con sus potencialidades concurrentes. Arendt entiende que ambos aspectos están contenidos en la experiencia revolucionaria 0 , en sus términos, en el "espíritu revolucionario"88. En otras palabras, el "espíritu de la revolución" une dos elementos solo en apariencia incompatibles. El primero es "el acto de la fundación de un nuevo cuerpo político" y remite a la experiencia de la novedad que acaece en la fundación. Al mismo tiempo, tal acto "involucra la grave preocupación [grave concern] por la estabilidad y la durabilidad de la nueva estructura"89. Es la "experiencia que aquellos comprometidos en esta gravosa tarea [grave business] deben tener", a saber, "la extraordinaria toma de consciencia [exhilarating awareness] de la capacidad humana de comenzar". Atrapados en el momento pasmoso de la creación, la revolución enciende "la exaltación del espíritu [high spirits] que siempre asiste al nacimiento de algo nuevo en la tierra"90. Para Arendt, el aspecto fundacional y performativo de la praxis, que contiene el elemento del cambio y la transformación, conlleva, también, el deseo de fundar estructuras estables y sólidas. En suma, el espíritu revolucionario incluye tanto el júbilo y la euforia compatibles con los actos de derribar y construir, como también la mesura y la tranquilidad provenientes de las estructuras perdurables.

88. Cf. Arendt, Hannah, On Revolution, op. cit.; pp. 214-216.

89. Cf. idem, p. 215

90. Cf. ibidem. 
Desde el punto de vista de la categoría de poder, clave en Arendt, el poder plural (diametralmente contrario a la violencia, que puede ser unipersonal) surge cuando muchos actúan juntos ${ }^{91}$. Ese poder de instituir, que emerge cuando los hombres se reúnen para actuar, es efímero e inestable, hasta tanto sea "reificado"92, es decir institucionalizado en leyes, estatutos, constituciones. Estos dispositivos de poder instituido establecen un espacio público duradero y sólido. En On Violence, apunta la autora: "El poder surge siempre que los hombres se reúnan y actuen en concierto, (...) pero deriva su legitimidad de la acción conjunta inicial [from the initial getting together]." Según esto, la legitimidad de dicho poder se relaciona "con una apelación al pasado"93; sin embargo, las instituciones legítimas son "manifestaciones y materializaciones de poder; se petrifican y decaen tan pronto como el poder vivo del pueblo deja de sostenerlos" ${ }^{\prime 94}$. En consecuencia, el poder no sólo se manifiesta originariamente en el momento fundacional, cuando muchos se reúnen para hablar o actuar (praxis y lexis), sino que debe perdurar activo como savia que vivifica las instituciones. Dicho con Arendt, el poder también es "aquello que mantiene en existencia el espacio público [public space], el espacio potencial de aparición que acaece entre los hombres, en calidad de agentes y de oradores". ${ }^{95}$ El ámbito público es un es-

91. Cf. Arendt, H, The Human Condition, op. cit.; pp. 199-206.

92. Cf. idem, p. 139.

93. Hannah Arendt, "On Violence," in Crises of the Republic, Harcourt Brace Jovanovich. Inc., New York, 1972; cf. p. 150.

94. Cf. idem, p. 140.

95. Cf. Arendt, Hannah, The Human Condition, op. cit, ; p. 200 (el énfasis es añadido). pacio potencial, como señala el fragmento antedicho, tan potencial como el poder que generan muchos para actuar y para hablar. Insistimos, ese puro poder de instituir es inestable e impresiso hasta tanto no se instituya en estatuto o constitución. Al mismo tiempo, debe perdurar latente y animar todas las instituciones, ya que dicho poder es el vínculo con el origen legitimante. Vemos así, que a causa de la misma naturaleza potencial del poder ${ }^{96}$, es imperativo el establecimiento de instituciones o de canales sancionados por la Constitución, que garanticen la acción permanente de los ciudadanos, so pena de debilitar y osificar sus instituciones. En este particular aspecto, Arendt es deudora de Jefferson y de su percepción de la indeclinable necesidad del sistema de consejos.

Richard Bernstein denomina este aspecto equívoco de la praxis como "la paradoja de la fundación"97. El propósito de una revolución es fundar una nueva Constitución. La libertad tangible que aparece a la vista de todos en los espacios públicos recién creados es la misma actividad instituyente de la fundación, que coincide con el acto de diseñar una nueva Constitución. Paradójicamente, el mayor peligro que enfrenta una Revolución es que su éxito puede echarse a perder si las instituciones creadas ahogan el espíritu revolucionario que las originó. Es decir, la paradoja consiste en que solo los fundadores parecen poder

96. Cf. Arendt, Hannah, The Human Condition, op. cit.; p. 200. Arendt esclarece la procedencia etimológica del término poder en alemán (Die Macht) para poner en evidencia su carácter potencial. Die Macht proviene de mögen y möglich (poder y posible, respectivamente).

97. Richard Bernstein, Hannah Arendt and the Jewish Question, Polity Press, Cambridge, UK; cf. position 2683 (e-book). 
gozar de la libertad pública y de la felicidad pública inherentes al momento instituyente. Arendt sostiene que Jefferson fue el único pensador político americano que "percibió mejor que nadie, con gran claridad y apasionada preocupación, esta debilidad -en apariencia inevitable- de la estructura de la República". Fue Jefferson quien exigió la división de la república en consejos, a los que llamó "repúblicas elementales [elementary republics]" con el fin de renovar el espíritu revolucionario de la generación fundadora, la savia nutriente que podía mantener viva a la República. Si su proyecto de las "repúblicas elementales" se hubiese implementado, consigna Arendt, hubiéramos asistido a una réplica de esa forma novel de gobierno que podemos detectar en las sociedades populares de la Revolución francesa y en las secciones de la Comuna de París de fines del XIX, entre otros acontecimientos ejemplares y sobresalientes de la "tradición revolucionaria perdida", que On Revolution pone en evidencia. ${ }^{99}$

Cuando Hannah Arendt examina la Revolución en los EEUU, valora las enseñanzas de T. Jefferson y advierte que los padres fundadores "fallaron en incorporar el municipio y la comuna [the township and the town hall meeting] en la Constitución"100. Los municipios (o ayuntamientos) eran "espacios de libertad [spaces of freedom]" ${ }^{101}$; como tales eran las instituciones cruciales de la nueva República. La vida del hombre libre -apunta Arendt- necesita de espacios acondicionados para congregarse en calidad de

98. Cf. Hannah Arendt, On Revolution, op. cit.; pp. 258, 284.

99. Cf. idem, pp. 207 y siguientes.

100. Cf. idem; pp. 231, 242.

101. Cf. idem, p. 256. ciudadanos, "el espacio específicamente político, donde los hombres de reúnen como ciudadanos, no como personas privadas" ${ }^{102}$. Es decir, la vida pública y la libertad pública que la acompaña, exigen foros institucionalmente reconocidos para la acción libre, en donde los ciudadanos se manifiestan unos a otros, en la acción y en la palabra. Arendt insiste en la importancia política de "the ward system"103 y destaca la relevancia de estos espacios instituidos porque contribuyen a mantener un estilo de vida -la vida ciudadana- a la que no debemos renunciar. El aspecto clave del consejo no es tanto los procesos de decisión y el logro de objetivos concretos, sino que estos foros garantizan un espacio para que los hombres puedan comportarse como ciudadanos, reuniéndose, discutiendo, argumentando e ilustrándose mutuamente con sus opiniones ${ }^{104}$. En una palabra: poniendo en evidencia que les importa algo más que su estrecho bienestar privado; en esto radica -para Hannah Arendt- la relevancia de la praxis mancomunada como expresión más excelsa de nuestra humanidad. Para Hannah Arendt esta actividad -esencialmente política- es un fin en sí mismo. No necesita remitirse a los propósitos y objetivos, para ser significativa. Su especial interés en el Jefferson republicano, con sus ideas sobre los municipios, la participación activa garantizada, y con la división de la república en consejos, no se debe a una actitud nostálgica de las decisiones directas de las antiguas polis griegas, pese a su reluctancia hacia la representación política. Arendt desea rescatar otra cosa. Las sociedades o clubes revolucionarios en Francia, y los wards virginianos no se establecieron ne-

102. Cf. idem, p. 21.

103. Cf. idem, p. 321.

104. Cf. idem, p. 238. 
cesariamente para la toma de decisiones, o para las funciones ejecutivas; su objetivo no era solo el gobierno o la administración de un municipio, sino asegurar un ámbito para la discusión, el debate y la conversación. En On Revolution, por ejemplo, Arendt valora particularmente un club francés que se había impuesto a sí mismo la prohibición de tener algún tipo de influencia en la Asamblea General. El club existía solamente "para conversar sobre [los asuntos públicos] y para intercambiar opiniones, sin la necesidad de plantear propuestas, hacer peticiones, nombramientos, y cosas por el estilo"105. De la misma manera, los consejos eran un espacio de libertad, un lugar donde la gente se podía reunir y discutir sobre cuestiones del día, comunes a todos. Su importancia no recae -como vemos- en sus logros, o en los fines que consiguen, sino en lo que fomentan y promueven. Como espacios institucionales de experiencia política organizada, los consejos ideados por Jefferson, recreaban y fomentaban la emulación de las pasiones y acciones pasadas; ofrecían la experiencia de la acción libre y de la felicidad pública, que son posibles solamente en el proceso de la acción conjunta y de la conversación con otros. Veamos la cuestión en los escritos de T. Jefferson.

En Notes on The State of Virginia (1784), Jefferson escribió que deseaba "dividir cada condado en pequeños distritos de cinco o seis millas cuadradas, llamados cientos [hundreds]"106. Un año más tar-

105. Cf. idem, p. 225.

106. "Hundreds" se refiere a cien varones cabezas de familia. En origen, la propuesta tenía fines educativos. "This bill proposes to lay off every country into small districts of five or six miles square, called hundreds and in each of them to establish a school for teaching, reading, writing, de, con la aprobación de la Land Act de 1785 (que establecía que una sección por municipio debería reservarse para propósitos educativos), la idea se convirtió en ley. Treinta años más tarde, cuando las tres ramas del gobierno federal -ejecutivo, legislativo y judicial- habían crecido desmesuradamente en poder en relación a los gobiernos locales, Jefferson insistió en la relevancia política de su idea de los wards, que combinaba todos los requisitos de una república en miniatura: participación y auto-gobierno en un territorio pequeño. En la carta del 31 de enero de 1814 dirigida a Joseph Cabell, Jefferson alude al Estado de Virginia y le confía su antiguo anhelo: "hace tiempo que creo que la subdivisión del condado [county] en consejos [wards] es la medida fundamental para asegurar la continuidad del gobierno republicano"107. Dos años después, el 2 de febrero de 1816, se dirigió al mismo destinatario precisando su propuesta en relación a la naturaleza de las funciones del consejo: "que al gobierno nacional le sea confiada la defensa de la nación y sus relaciones extranjeras y federales. A los gobiernos estatales [se les confíen] los derechos civiles, las leyes, la policía y la administración de lo que le concierne generalmente al estado. A los condados les compete los asuntos [concerns] locales; y cada consejo dirige los

and arithmetic". Véase Jefferson, Thomas, The Works of Thomas Jefferson, Federal Edition (New York and London, G.P. Putnam's Sons, 1904-5). Vol. 4. [Online] available from http://oll.libertyfund.org/titles/756; accesed 13/2/2018; Internet. (Formato Ebook pdf). Cf. Query 14, p. 39.

107. Jefferson, Thomas, The Works of Thomas Jefferson, Federal Edition (New York and London, G.P. Putnam's Sons, 1904-5). Vol. 11. [Online] available from http://oll.libertyfund.org/ titles/807; accesed 13/2/2018; Internet. (Formato Ebook pdf); cf. p. 219. 
intereses que le son pertinentes a sí mismos". Jefferson explica la gradación de autoridades, de abajo hacia arriba, siendo la fuente de la autoridad de toda la estructura de la unión, el poder que nace en los consejos. Se trata, entonces, de una estructura piramidal inversa respecto de las jerarquías tradicionales. Alude a una aristocracia de virtud y mérito, cuya fuente de autoridad es la base, es decir, los municipios o los ayuntamientos: "Las repúblicas elementales de los consejos, las repúblicas del condado, las repúblicas de los Estados y la república de la Unión, formarían una gradación de autoridades, basadas en la ley, manteniendo cada una su participación delegada de poderes" ${ }^{108}$.

Ahora bien, ¿cuáles eran los intereses y las obligaciones de los consejos específicamente? En una carta a Samuel Kercheval el 12 de julio de 1816 esclarece los intereses que deben confiarse a los consejos. Idealmente, estos incluían la elección, la instalación y el soporte de una amplia variedad de servicios, que en ese momento estaban bajo la dirección de autoridades distantes, a saber: jueces, una escuela militar para educar jóvenes, patrullas de vigilancia, equipos de mantenimiento de rutas, el cuidado de los enfermos y los pobres. En resumen, a juicio de Jefferson, los municipios debían funcionar como repúblicas en miniatura. Su proyecto era dividir y subdividir las repúblicas del poder central por medio de la subordinación a las estructuras más próximas al pueblo (o sea, la subordinación era de arriba hacia abajo: Nación, Estados, Condados,

108. http://press-pubs.uchicago.edu/founders/do cuments/v1ch4s34.html. No hemos encontrado la carta del 2 de febrero de 1816 dirigida a J. Cabell en la biblioteca on line de Liberty Fund, de donde proceden el resto de las citas de las obras y cartas de T. Jefferson. municipios -wards o town hall meetings-) para, finalmente, terminar en "la administración de la propia granja", para beneficio de todos. Para Jefferson, el elemento decisivo para "cementar" el todo, es decir, la Unión, era la participación en los asuntos públicos: "And the whole is cemented by giving to every citizen, personally, a part in the administration of the public affairs". La clave, explicaba Jefferson, era "asignar las tareas según las competencias de las personas" y "poner bajo su supervisión lo que puede gestionar". De esta forma cada ciudadano se transforma en "un miembro activo del gobierno" y no en un mero votante que solo ejerce su ciudadanía el día del sufragio ${ }^{109}$.

\section{Conclusión}

En conclusión, en su obra de 1963, On Revolution, Hannah Arendt ha puesto en evidencia las raíces republicanas de la Revolución estadounidense, en desmedro de su interpretación habitual en el contexto de las ideas del liberalismo clásico. Empleando sus propias categorías de pensamiento -espacio público, praxis mancomunada y poder- la autora indagó la experiencia revolucionaria y colonial estadounidense señalando allí el poder performativo de pactos y acuerdos, y la acción en concierto que elude las finalidades particulares de los agentes, para seguir sus propia lógica estableciendo instituciones duraderas y transmisibles. Pero la acción y el discurso, hemos visto, involucran también el instante inaugural

109. Cf. Jefferson, Thomas, The Works of Thomas Jefferson, Federal Edition (New York and London, G.P. Putnam's Sons, 1904-5). Vol. 12. [Online] available from http://oll.libertyfund. org/titles/808; accesed 13/2/2018; Internet. (Formato Ebook pdf); cf. pp. 13-18. 
de la fundación. Inexcusablemente, el nuevo origen ${ }^{110}$ que pone en existencia un nuevo cuerpo político y que es el esfuerzo conjunto de muchos, ha de pervivir intacto alimentando y sosteniendo la vitalidad de las instituciones. Esta particular convicción del Thomas Jefferson republicano, celebrada y compartida por Arendt, se evidencia en su insistencia en incorporar las unidades políticas básicas (consejos, municipios o distritos) como foros institucionalizados de participación ciudadana.

Cierto es que el padre fundador admite y, hasta cierto punto, amalgama los motivos del liberalismo (fuertemente presentes en los años previos a la Revolución) y los del republicanismo. Sin embargo, tras la novedosa lectura que Arendt propone, la figura de Thomas Jefferson integra la corriente del republicanismo clásico en forma eminente. En este punto, Hannah Arendt desliza su propia posición sobre el concepto de lo político hacia la interpretación del autor de la Declaración de la Independencia. Cuando Jefferson exigió la división de los condados en distritos (consejos o wards, en Virginia y town hall meetings, en New England) como enmienda constitucional -sostiene Arendt- sabía que

110. Cf, Arendt, Hannah, "Never-Before-Published Hannah Arendt on What Freedom and Revolution Really Mean", New England Review, Volume 38, Number 2, 2017. En la página 4, leemos : "And in part it is because nothing in the course of these revolutions is as conspicuous and striking as the emphatic stress on novelty, repeated over and over by actors and spectators alike, in their insistence that nothing comparable in significance and grandeur had ever happened before. The crucial and difficult point is that the enormous pathos of the new era, the Novus Ordo Seclorum, which is still inscribed on our dollar bills, came to the fore only after the actors, much against their will, had reached a point of no return". se debían proveer canales institucionalizados por medio de los cuales los ciudadanos tendrían la oportunidad de ser republicanos, es decir, de comportarse como ciudadanos en forma permanente, y no solamente el día de la votación. Entendemos que el enaltecimiento de la vita activa y particularmente de la praxis, celebrado por Arendt en The Human Condition, encuentra su réplica en la exigencia de Thomas Jefferson en el compromiso sostenido y la participación vigorosa de cualquier ciudadano en los asuntos comunes. Arendt cree que esta actividad era para el tercer presidente de los EEUU un fin en sí mismo, es decir, que el valor de la acción y el discurso yace en ellos mismos, más allá de la consecución de los fines y los propósitos de los agentes. Como no son meros medios instrumentales, sino el medium o el ambiente propicio para el despliegue de las actividades esencialmente humanas (ni animales, ni divinas), entonces la política es también un fin en sí mismo. Hannah Arendt entiende que esta nota es esencial al republicanismo de T. Jefferson y, en consecuencia, concertar voluntades, actuar junto a otros y conversar sobre todo lo que nos concierne como ciudadanos poseen un valor inherente y una significación propia allende los propósitos estrechos de los actores.

En este contexto, Arendt minimiza la asombrosa posición de Jefferson sobre la promisoria modalidad de las revoluciones recurrentes ${ }^{111}$, que consistía en volver a foja cero cada veinte años, de manera que con cada recambio generacional, los recién llegados (los principiantes ["begin-

111. Thomas Jefferson, The Works of Thomas Jefferson, Federal Edition (New York and London, G.P. Putnam's Sons, 1904-5). Vol. 6. [Online] available from https://oll.libertyfund.org/ titles/803; accessed 3/12/2018; Internet. 
ners"] de Arendt ${ }^{112}$ ) mantuvieran vivo el espíritu revolucionario, cuyo más propio sentido coincide con la energía fundacional y el poder constituyente. Cierto es la que la pensadora atempera las opiniones radicales de Jefferson sobre la prerrogativa de las generaciones de cuestionar la forma de gobierno del mundo al que ingresan y -en consecuencia- de modificar su Constitución. Sin embargo, coincide con el admirador de la Revolución en Francia, en que sin los órganos básicos que canalicen la participación ciudadana, el pueblo -eventualmente- recurrirá a la fuerza y la rebelión para expresar su fastidio $^{113}$. En opinión en Arendt, Thomas Jefferson creía que el sistema de consejos podía ofrecer:

"una exacta repetición de todo el proceso de acción que había acompañado el curso de la Revolución [...]. Y [en] sus últimos escritos estaba enteramente concernido por el acto de hacer una constitución y el establecimiento de un nuevo gobierno, esto es, por aquellas actividades que por sí mismas constituyen el espacio de libertad [freedom]".

112. Cf. Arendt, Hannah, The Human Condition, op. cit.; pp. 177, 189.

113. En la carta del 4 de septiembre de 1823 a su rival electoral y amigo, John Adams, Jefferson defiende las revoluciones, en general, y la francesa, en particular, como el paso "del despotismo a la libertad". Los pueblos deben aprender a ser libres y necesitan de varias generaciones para instituir repúblicas, porque "la generación que comienza una revolución raramente la completa" y usualmente "[estos] terminan siendo instrumentos en las manos de los Bonapartes, que derrotan sus derechos y propósitos". Un "primer intento de auto-gobierno puede fallar, como también un segundo y un tercer intento", sin embargo -eventualmente- "alguno de los intentos renovados, tendrá éxito". Véase, http://oll.libertyfund.org/ title/808; cf. p. 190.
(Arendt, Hannah, On Revolution, op. cit.; cf. p. 230).

Dicho espíritu revolucionario, que yacía en la conciencia del poder del pacto, había nutrido el país desde la época colonial e inclusive pre-colonial (si nos atenemos al ejemplo del Mayflower Compact, caro a Arendt) y sólo podía perdurar activo "[...] si se incorporaban y se constituían debidamente, se re-fundaban las fuentes originales de su poder y de la felicidad pública"114. Para Thomas Jefferson, los consejos eran "la más sabia invención [...] del ingenio humano, para el perfecto ejercicio del auto-gobierno, y para su preservación"115.

114. Cf. Arendt, Hannah, On Revolution, op. cit.; cf. p. 231.

115. Cf. Jefferson, Thomas, The Works of Thomas Jefferson, Federal Edition (New York and London, G.P. Putnam's Sons, 1904-5). Vol. 12. [Online] available from http://oll.libertyfund. org/titles/808; accesed 13/2/2018; Internet. (Formato Ebook pdf); cf. p. 15. 